\title{
Lateralization in cluster headache: a Nordic multicenter study
}

\author{
Eva Laudon Meyer - Katarina Laurell - Ville Artto - Lars Bendtsen · \\ Mattias Linde $\cdot$ Mikko Kallela $\cdot$ Erling Tronvik $\cdot$ John-Anker Zwart · \\ Rikke M. Jensen $\cdot$ Knut Hagen
}

Received: 23 March 2009/Accepted: 7 May 2009/Published online: 3 June 2009

(C) Springer-Verlag 2009

\begin{abstract}
A slight predominance of cluster pain on the right side has been reported in several studies. The aim of this large retrospective Nordic multicenter study was to estimate the prevalence of right- and left-sided pain in cluster headache $(\mathrm{CH})$ patients with side-locked pain, the prevalence of side shifts in episodic and chronic $\mathrm{CH}$ patients, and the occurrence of cranial autonomic symptoms related to pain side. Among 383 cluster patients, 55 (14\%) had experienced pain side shift. Of the remaining 328 individuals without side shift, there was no significant difference between the occurrence of right-sided and leftsided pain (54 vs. $46 \%$ ). The prevalence of side shift was similar for episodic and chronic $\mathrm{CH}$ and the occurrence of
\end{abstract}

\section{E. L. Meyer}

Department of Clinical Neuroscience,

Division of Neurology at Karolinska Insitutet,

Stockholm, Sweden

K. Laurell

Department of Neuroscience, Neurology,

Uppsala University, Uppsala, Sweden

\section{Artto $\cdot$ M. Kallela}

Department of Neurology,

Helsinki University Central Hospital, Helsinki, Finland

L. Bendtsen · R. M. Jensen

Department of Neurology, Danish Headache Centre,

University of Copenhagen, Glostrup Hospital,

Glostrup, Denmark

M. Linde

Cephalea Headache Centre, Gothenburg, Sweden

M. Linde

Institute of Neuroscience and Physiology,

The Sahlgrenska Academy, University of Gothenburg,

Gothenburg, Sweden cranial autonomic symptoms was not influenced by the pain side. In conclusion, previous reports of a side difference in location of cluster pain could not be confirmed in this large Nordic sample.

Keywords Pain side $\cdot$ Headache $\cdot$ Scandinavian

\section{Introduction}

Cluster headache $(\mathrm{CH})$ is characterized by severe unilateral headache attacks. In episodic $\mathrm{CH}$, the attacks appear in episodes for weeks or months separated by pain-free

\footnotetext{
E. Tronvik · J.-A. Zwart · K. Hagen

Department of Neuroscience, Faculty of Medicine,

Norwegian University of Science and Technology,

7489 Trondheim, Norway

E. Tronvik · K. Hagen $(\bowtie)$

Section of Neurology, Norwegian National Headache Centre,

St. Olavs Hospital, 7006 Trondheim, Norway

e-mail: knut.hagen@ntnu.no

J.-A. Zwart

Department of Neurology, Ullevaal University Hospital, University of Oslo, 0450 Oslo, Norway
} 
remission periods, whereas chronic $\mathrm{CH}(\mathrm{CCH})$ occurs without remission periods or with remissions less than 1 month [1]. The headache attacks are often accompanied by ipsilateral, cranial autonomic symptoms [2] and also associated with various cardiovascular changes indicating a systemic, autonomic disturbance as well [3, 4]. The etiology of $\mathrm{CH}$ is still not fully understood, but findings from neuroimaging studies, as well as the treatment response of deep brain stimulation (DBS) in some patients refractory to medication, strongly suggest the involvement of the ipsilateral hypothalamus, particularly in the active headache period [5-7].

Cluster headache attacks are almost always unilateral and in general affecting the same side of the head from attack to attack. However, some studies report side shifts between active periods and more seldom between attacks $[8,9]$, of which the latter may be particularly common in chronic $\mathrm{CH}[8,10]$.

The knowledge about lateralization and side shifts of the pain in $\mathrm{CH}$ is limited but of clinical relevance, since the occurrence of side shifts has to be considered prior surgical treatment in chronic $\mathrm{CH}$ patients. A slight predominance of cluster pain on the right side has been reported in a review of five different studies $(n=807)$ [11] and among 230 patients from England [8], whereas two Italian authors report conflicting findings [12,13]. Moreover, Nappi et al. [13] suggest the occurrence of local autonomic symptoms to be more common in right-sided than left-sided cluster pain, and Micieli et al. [14] report patients with right-sided pain to have lower mean day time heart rate compared with patients with left-sided pain and controls. A possible relationship between pain side and autonomic symptoms in $\mathrm{CH}$ is of pathophysiological interest because lateralization of sympathetic cardiovascular control to the right insula has been found in studies of both animals and humans $[15,16]$.

The aim of this large Nordic multicenter study was to estimate the pain side prevalence in $\mathrm{CH}$ patients with sidelocked pain, the prevalence of side shifts in episodic and chronic $\mathrm{CH}$ patients, and if the occurrence of cranial autonomic symptoms is related to pain side.

\section{Materials and methods}

This retrospective study was initiated by the Nordic Headache Innovators (NHI) network and was approved by the Regional Committee for Ethics in Medical Research in Norway, the Norwegian Data Inspectorate and the Regional Ethics committee in Stockholm, Sweden when applicable. Ethics approval is not required for retrospective chart reviews in Sweden, Finland or Denmark.

\section{Patients}

All patients with cluster headache were diagnosed by neurologists and fulfilled the criteria of the International Headache Society [1]. They were retrospectively identified from data files in four Nordic countries, and information of pain side and the occurrence and nature of cranial autonomic symptoms were collected and analyzed. $\mathrm{CH}$ patients from the Norwegian National Headache Centre in Trondheim, Norway $(n=85)$ were identified from the list of headache patients consecutively included in a Headache Biobank constituted October 2004 and had all filled in a detailed questionnaire at the inclusion time. Some of the Swedish CH patients ( $n=27$ ) (Department of Neurology, Karolinska University Hospital) were identified from previous $\mathrm{CH}$ studies and appropriate data of clinical symptoms were collected from questionnaires. $\mathrm{CH}$ patients from Denmark $(n=132)$ (Danish Headache Centre, Glostrup), Finland $(n=15)$ (Helsinki Headache Centre), Sweden $(n=81)$ (Cephalea Headache Centre, and Department of Neurology, Karolinska University Hospital, Huddinge), and Oslo, Norway $(n=43)$ (Ullevål University Hospital) were identified in medical records from current consulters and previously treated patients.

\section{Headache data}

Information on sex, age, cluster headache type (episodic or chronic), pain side, type and number of autonomic symptoms were collected from medical records and/or questionnaires. The number of cases with complete data was $371(97 \%)$ for lacrimation, 367 (96\%) for nasal congestion, $351(92 \%)$ for nasal rhinorrhea, $350(91 \%)$ for conjuntival injection, 337 (88\%) for ptosis, and 262 (69\%) for miosis.

\section{Power calculation}

Previously, a summary of five different studies involving a total of $807 \mathrm{CH}$ patients without side shift revealed that $44 \%$ had pain in the left side and 56\% in the right side [11]. Assuming a difference in prevalence of $12 \%$, using a power of 0.80 and a significance level of $5 \%$, a minimum of 280 patients without side shift had to be included in the present study.

\section{Statistics}

Baseline data were evaluated with the chi-square test (categorical variables) and ANOVA analysis (continuous variable). Pain side occurrence was evaluated by binominal test, whereas the comparison of autonomic symptoms between pain sides was conducted using chi-square and 
Kruskal-Wallis test. Missing values were labeled as 0 if the mean number of autonomic symptoms was calculated.

\section{Results}

As shown in Table 1, no significant relationship was found between pain side and sex, mean age, or cluster type (episodic or chronic). Among a total of 383 cluster patients, $55(14 \%)$ had experienced pain side shifts. The prevalence of pain side shift was not significantly different between individuals with chronic and episodic $\mathrm{CH}$ (13 vs. $15 \%$, $P=0.60$ ). Of the remaining 328 individuals without side shift, right-sided pain tended to be slightly more common than left-sided pain (54 vs. $46 \%, P=0.14$ ).

Autonomic symptoms were found in $96 \%$ of the patients with no significant difference between patients with pain in the left side, right side or those with side shift $(P=0.74)$. The mean number of autonomic symptoms did not differ between the pain sides ( $P=0.42)$ (Fig. 1).

No difference between left- and right-sided pain was found regarding the proportion of individuals with the combination of ptosis and miosis (13 vs. $16 \%, P=0.70$ ), or the combination of lacrimation, nasal congestion, rhinorrhea, and conjunctival injection (25 vs. $30 \%, P=0.25$ ).

Table 1 Patients characteristics

\begin{tabular}{lccclc}
\hline Variable & Overall & Left side & Right side & Side shift & $P$ value \\
\hline Number & 383 & 150 & 178 & 55 & \\
Female (\%) & 26 & 27 & 28 & 22 & 0.70 \\
Age (mean) & 47 & 47 & 46 & 49 & 0.40 \\
Episodic (\%) & 74 & 74 & 73 & 78 & 0.64 \\
Chronic (\%) & 26 & 26 & 27 & 22 & \\
\hline
\end{tabular}

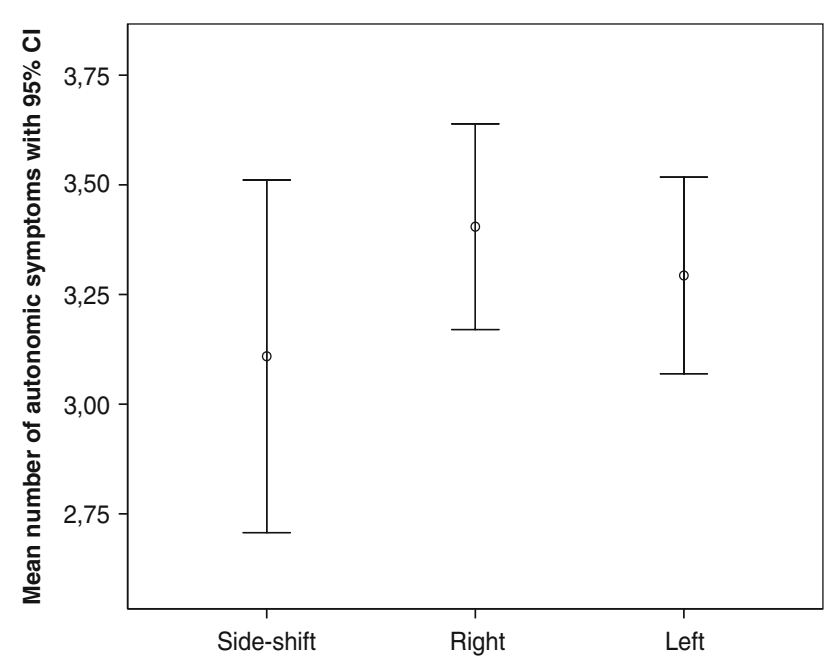

Fig. 1 Mean number of autonomic symptoms with 95\% confidence interval (CI) for different status of pain side
The mean bout duration was 6.3 weeks (95\% CI 5.57.0 weeks) among the 285 individuals with episodic cluster headache.

\section{Discussion}

This large retrospective multicenter study in the Nordic countries demonstrated no significant difference in side location of the pain in $\mathrm{CH}$ patients, which is in accordance with the results of another large study of 608 patients from Italy [12]. Also in previous studies, indicating a predominance of right-sided pain during attacks (47-60\%) [8, 9, 16], there were lack of information of statistical significant findings. A sufficient statistical power was reached by the sample of 383 Nordic patients, and the present study did not indicate a difference in pain side location of clinical interest. A summery of nine different studies with a sample size of at least 50 patients (Table 2) [8, 9, 12, 13, 17-20] showed that right-sided pain was slightly more common than left-sided pain (47 vs. $41 \%, P=0.006$ ). However, it should be emphasized that this difference was not significant (52 vs. $48 \%, P=0.24$ ) for the four studies performed after 1988 when the criteria from the Headache Classification Committee was published [21]. It cannot be ruled out that the slight predominance of right-sided pain may reflect a selection bias related to clinical-based studies. This selection bias is probably not a major problem in population-based studies. However, although right-sided pain seem to be more common ( 58 vs. $42 \%, P=0.77$ ) in a summary of three epidemiological studies, a total sample size of 12 patients is too low to make a firm conclusion [22-24].

In the present study, $14 \%$ of the patients had experienced side shifts of the pain. This is in accordance with the previous studies, which report side shifts in 10-16\% of the patients [9, 13, 17]. There are reports of side shifts being significantly more common in chronic than in episodic $\mathrm{CH}$. For example, side shifts within the bout were reported in $14 \%$ of episodic $\mathrm{CH}$ patients compared with $33 \%$ in chronic $\mathrm{CH}$ patients [8]. In the present study, we found similar occurrence of side shifts in episodic and chronic $\mathrm{CH}$ patients. Since data were retrospectively collected from medical records, it was not possible to distinguish between side shifts within and between the active periods. In a recent paper from Leone et al. side shifts were reported in as many as $51 \%$ of 63 chronic $\mathrm{CH}$ patients consecutively evaluated between 1999 and 2007 [10]. However, there is no information whether a majority of these patients were severely affected by the disease. Side shifts may be associated with the long duration of the cluster periods [9]. If so, a high number of patients with $\mathrm{CCH}$, refractory to medication, would explain a high rate of side shifts. 
Table 2 Summary of studies evaluating laterality of pain in cluster headache

\begin{tabular}{lcccc}
\hline References & Number of patients & Right side $(\%)$ & Left side (\%) & Side shift $(\%)$ \\
\hline Sutherland and Eadie [18] & 58 & $28(48)$ & $24(41)$ & $6(11)$ \\
Ekbom [9] & 105 & $51(49)$ & $40(38)$ & $14(13)$ \\
Lance and Anthony [19] & 60 & $32(53)$ & $23(38)$ & $5(9)$ \\
Kudrow [20] & 423 & $199(47)$ & $165(39)$ & $59(14)$ \\
Manzoni et al. [17] & 180 & $88(49)$ & $135(54)$ & $28(16)$ \\
Nappi et al [13] & 251 & $138(60)$ & $87(38)$ & $27(11)$ \\
Bahra et al. [8] & 230 & $275(45)$ & $264(43)$ & $5(2)$ \\
Cademartiri et al. [12] & 608 & $178(46)$ & $150(39)$ & $69(11)$ \\
Present study & 383 & $1,078(47)^{\#}$ & $952(41)^{\#}$ & $55(14)$ \\
Overall & 2,298 & & $268(12)$ \\
\hline
\end{tabular}

$\# P=0.006$ binominal test

Unfortunately, the age of onset of cluster headache was not available in the majority of cases in the present study.

The absolute majority (96\%) of the patients had at least one cranial autonomic symptom during the attacks. The side location of the pain did not influence whether autonomic symptoms occurred, or not. Moreover, the mean number of autonomic symptoms was not influenced by the side of the pain. In contrast, cranial autonomic symptoms were in another large study more common in patients with right-sided pain or side shifts than in patients with leftsided pain, and an association between the occurrence of cranial autonomic symptoms and attack frequency was also demonstrated [13].

A limitation of this study is that the data were retrospectively collected which increase the risk for incorrect reporting. However, since the typical pain in $\mathrm{CH}$ is sidelocked and recurrent for many years, the report of the pain side should be reliable. A neurologist diagnosed all patients, which increase the diagnostic accuracy.

In conclusion, this large Nordic retrospective multicenter study demonstrated no significant difference in side location of the pain in $\mathrm{CH}$ patients. Moreover, the prevalence of side shift was similar for episodic and chronic $\mathrm{CH}$ and the occurrence of cranial autonomic symptoms was not influenced by the pain side.

Acknowledgments Conferences in the Nordic Headache Innovators (NHI) network group were supported by Astra Zeneca and MSD.

Conflict of interest None.

\section{References}

1. Headache Classification Subcommittee of the International Headache Society (2004) The international classification of headache disorders: 2nd edn. Cephalalgia 24 (Suppl 1):1-160
2. Drummond PD (1988) Autonomic disturbances in cluster headache. Brain 111:1199-1209. doi:10.1093/brain/111.5.1199

3. Russell D, Storstein L (1983) Cluster headache: a computerized analysis of $24 \mathrm{~h}$ Holter ECG recordings and description of ECG rhythm disturbances. Cephalalgia 3:83-107. doi:10.1046/j.14682982.1983.0302083.x

4. De Marinis M, Strano S, Granata M et al (1995) Sympatheticparasympathetic activation during spontaneous attacks of cluster headache: evaluation by spectral analysis of heart-rate fluctuations. Cephalalgia 15:504-510. doi:10.1046/j.1468-2982.1995. 1506504.x

5. May A, Bahra A, Buchel C, Frackowiak RS, Goadsby PJ (1998) Hypothalamic activation in cluster headache attacks. Lancet 352:275-278. doi:10.1016/S0140-6736(98)02470-2

6. May A, Ashburner J, Buchel C et al (1999) Correlation between structural and functional changes in brain in an idiopathic headache syndrome. Nat Med 5:836-838. doi:10.1038/10561

7. Franzini A, Ferroli P, Leone M, Broggi G (2003) Stimulation of the posterior hypothalamus for treatment of chronic intractable cluster headaches: first reported series. Neurosurgery 52:10951099. doi:10.1227/01.NEU.0000057698.29634.D6

8. Bahra A, May A, Goadsby PJ (2002) Cluster headache: a prospective clinical study with diagnostic implications. Neurology 58:354-361

9. Ekbom K (1970) A clinical comparison of cluster headache and migraine. Acta Neurol Scand 46(Suppl 41):7-44

10. Leone M, Cecchini AP, Mea E, Tullo V, Bussone G (2008) Epidemiology of fixed unilateral headaches. Cephalalgia 28(Suppl 1):8-11. doi:10.1111/j.1468-2982.2008.01607.x

11. Sjaastad O (1990) Episodic cluster headache. In: Sjaastad O (ed) Cluster headache syndrome. Saunders, London, pp 35-268

12. Cademartiri C, Torelli P, Cologno D, Manzoni GC (2002) Upper and lower cluster headache: clinical and pathogenetic observations in 608 patients. Headache 42:630-637. doi:10.1046/j.15264610.2002.02150.x

13. Nappi G, Micieli G, Cavallini A, Zanferrari C, Sandrini G, Manzoni GC (1992) Accompanying symptoms of cluster attacks: their relevance to the diagnostic criteria. Cephalalgia 12:165168. doi:10.1046/j.1468-2982.1992.1203165.x

14. Micieli G, Cavallini A, Barzizza F, Rossi F, Nappi G (1993) Imbalance of heart rate regulation in cluster headache as based on continuous 24-h recordings. Clin Auton Res 3:291-298. doi: 10.1007/BF01827329

15. Critchley HD, Taggart P, Sutton PM et al (2005) Mental stress and sudden cardiac death: asymmetric midbrain activity as a linking mechanism. Brain 128:75-85. doi:10.1093/brain/awh324 
16. Oppenheimer S (2006) Cerebrogenic cardiac arrhythmias: cortical lateralization and clinical significance. Clin Auton Res 16:611. doi:10.1007/s10286-006-0276-0

17. Manzoni GC, Terzano MG, Bono G, Micieli G, Martucci N, Nappi G (1983) Cluster headache-clinical findings in 180 patients. Cephalalgia 3:21-30. doi:10.1046/j.1468-2982.1983.0301021.x

18. Sutherland JM, Eadie MJ (1970) Cluster headache. Res Clin Stud Headache 3:92-125

19. Lance JW, Anthony M (1971) Migrainous neuralgia or cluster headache? J Neurol Sci 13:401-414. doi:10.1016/0022-510X(71) 90003-7

20. Kudrow L (1980) In: Cluster headache: mechanisms and management. Oxford University Press, Oxford

21. Headache Classification Committee of the international Headache Society (1988) Classification and diagnostic criteria for headache disorders, cranial neuralgias, and facial pain. Cepahalalgia 8(Suppl 7):19-28. doi:10.1111/j.1468-2982.1991.tb00022.x

22. Sjaastad O, Bakketeig LS (2003) Cluster headache prevalence: Vågå study of headache epidemiology. Cephalalgia 23:528-533. doi:10.1046/j.1468-2982.2003.00585.x

23. Katsarava Z, Obermann M, Yoon MS, Dommes P, Kuznetsova J, Weimar C, Diener HC (2007) Prevalence of cluster headache in a population-based sample in Germany. Cephalalgia 27:10141019. doi:10.1111/j.1468-2982.2007.01380.x

24. Katsarava Z, Dzagnidze A, Kukava M et al (2009) Prevalence of cluster headache in the Republic of Georgia: results of a population-based study and methodological considerations. Cephalalgia Published online February 25 